\title{
Estampas sociolingüísticas del español de México en la Independencia, I: el indio bilingüe, el marginal, la mujer
}

\author{
Juan Antonio Frago* \\ Universidad de Zaragoza, España
}

\begin{abstract}
Resumen
La gran novela de Fernández de Lizardi aporta abundante y precisa información sobre el español de América en la época de las independencias, y sobre el de México en particular. El historiador puede encontrar en este corpus literario datos bastantes para una gruesa monografía descriptiva, y explicativa también, de esa importante sincronía de nuestra lengua en tierras americanas, con documentación suficiente de que fenómenos por algunos considerados de curso reciente ya habían cuajado por entonces. El Pensador Mexicano va entregando al lector estampas de la diversidad sociolingüística de su patria, con sucesivas situaciones novelescas en las que el buen hablar y el vulgar se contraponen, el de las clases bajas en ocasiones caracterizado con profusión formal. Queda así manifiesta la extrema dualidad normativa, o modélica, vigente en el México que se desgajaba de la hasta entonces metrópoli, a cuyo estudio se dedicarán varios artículos, que comienzan con este.
\end{abstract}

Para correspondencia, dirigirse a: Juan Antonio Frago Gracia (jafrago@unizar.es), Departamento de Lingüística General e Hispánica, Facultad de Filosofía y Letras, Universidad de Zaragoza, Pedro Cerbuna 12, 50009 Zaragoza, España. 
Palabras clave: español de México, normas culta y vulgar, el habla de la mujer, sociolingüística histórica.

Sociolinguistic images of Mexican Spanish during

THE INDEPENDENCE, I: THE BILINGUAL INDIAN, THE MARGINAL, THE WOMAN

\begin{abstract}
The great novel by Fernández de Lizardi provides abundant and precise information about American Spanish at the time of the Independence, the Mexican one in particular. In this literary corpus historians may find sufficient data for a bulky descriptive monograph, and explicative, as well, of that important synchrony of our language in American land, with adequate documentation that phenomena considered by some people as recent, had already consolidated. The Pensador Mexicano provides the reader with images about the sociolinguistic diversity of his homeland, where successive novelistic situations are opposed, lower class language being occasionally characterized with formal profusion. The extreme normative, or modellic, duality present in that Mexico breaking off from the metropolis is thus manifested. We shall devote several articles to the study of this phenomenon, starting with this one.
\end{abstract}

Key words: Mexican Spanish, educated and vulgar language, woman's language, historical sociolinguistics.

Recibido: 28/03/14 Aceptado: 20/05/14

\title{
1. LA CUESTIÓN NORMATIVA EN SU MARCO HISTÓRICO. CULTURA Y CORRECCIÓN IDIOMÁTICA EN EL PENSADOR MEXICANO ${ }^{1}$
}

1.1. Referencias a la diversidad regional de nuestra lengua se conocen desde el siglo XV, también opiniones sobre el buen y mal hablar, con atribución

\footnotetext{
1 Del Proyecto de Investigación FFI2013-45985, del Ministerio de Economía y Competitividad.
} 
de la preeminencia modélica a la corte, primero, después asimismo a Toledo en particular, sin que faltaran paladines de otras ciudades por ellos consideradas centros de la corrección idiomática. Pero tales atribuciones ya nacían con la marca del estereotipo por no fundamentarse en un mínimo razonamiento lingüístico, que, cuando llegó a hacerse, se basó en algún rasgo de pronunciación, que hoy se desecharía como criterio en la búsqueda de la excelencia normativa (el seseo o la articulación "gutural"). Y a semejantes estereotipos no pocos filólogos se han aferrado dogmáticamente, sin atender a la consistencia empírica que requiere toda identificación normativa en determinado marco local, que necesariamente habrá de ser social, pero impensablemente homogéneo. De la más elemental lógica es que el señalamiento de una norma, real o supuestamente vigente en un escenario geográfico, exige que antes se describan suficientemente el comportamiento de sus actores, los hablantes, para así establecer sus propias diferencias sociolingüísticas, y las que puedan mantener con individuos de otras naturalezas diatópicas.

El humanismo renacentista conllevó el interés del hombre de letras, y del culto en general, por la corrección idiomática, que más palpable se hace en la lengua escrita, con numerosos testimonios de ello en los textos de la época ${ }^{2}$. En uno del doctor Cristóbal de Acosta este autor anticipa en la dedicatoria Al lector su preferencia por la claridad en la exposición y no por el uso de un estilo alambicado, asendereada antinomia retórica por lo demás: "conozco que pudiera esto escrevirse en estilo más elegante, pero precio más dezir verdades ciertas que palabras limadas" (2005/1578: 2r) ${ }^{3}$, reconociendo asimismo la dificultad de la corrección en la obra escrita, sin duda mayor que la requerida por la expresión hablada: "Y los que, mouidos por inuidia, quisieren hazer lo contrario, ruégoles tomen primero la pluma en la mano y escriuan para sacar alguna cosa a la luz, y entonces se desengañarán, quánto más fácil es dezir mal que escreuir bien" $(2 \mathrm{v})$.

Pero mucha más información que la que sobre la diversidad sociolingüística y dialectal del español de los siglos XVI y XVII aportan humanistas interesados por el uso de la lengua (verbigracia Juan de Valdés,

\footnotetext{
2 A esta cuestión he dedicado un volumen monográfico (2002), y de ella me he ocupado en varios artículos, convencido de que para su dilucidación histórica siempre será muy útil la búsqueda de las opiniones que sobre el particular se vertieron en los textos, e incluso más aún del comportamiento ante el hecho normativo que los antiguos hablantes demuestran en su mismo manejo de la lengua escrita.

Como tantos otros, de este argumento se sirve el Inca Garcilaso de la Vega en su dedicatoria a Maximiliano de Austria: "Empero, considerado que para dezir verdad no es menester mucha retórica...” (1989/1590: 4r).
} 
Damasio de Frías, Bernardo de Aldrete y Juan Villar), o gramáticos (por ejemplo, Gonzalo Correas), incluidas explícitas menciones de hechos diferenciales en autores literarios (así las de Mateo Alemán, Miguel de Cervantes y Baltasar Gracián), se halla mediante el análisis de los textos, literarios y no literarios, que necesariamente ha de ser comparativo, o, lo que es lo mismo, basado en corpus cultural y diatópicamente diversos ${ }^{4}$. Porque es la pesquisa textual con mucho el mejor medio para establecer las normas, más apropiado sería decir modelos, que los hispanohablantes durante siglos siguieron, según el acertado juicio de Cervantes en el Quijote "la discreción es la gramática del buen lenguaje que se acompaña con el uso", pues "no pueden hablar tan bien los que se crían en las Tenerías y en Zocodover como los que pasean casi todo el día por el claustro de la Iglesia Mayor, y todos son toledanos" (II, 19), planteamiento en buena medida coincidente con el que sobre el particular mantiene Aguilita, personaje carcelario de Fernández de Lizardi (cfr. 3.2.). Esa era la "autoridad" normativa del hablar selecto hasta la fundación de la Real Academia Española, prácticamente hasta la independencia americana, y con mucha influencia modélica todavía hoy, papel de guía que Mateo Alemán atribuía a la lengua escrita de común aceptación, ampliado a los hablantes de reconocida aceptación ${ }^{5}$ :

la lengua castellana ha tenido quien escriva en ella con tanto cuidado y miramiento quanto sería menester para que hombre, quiriendo o dar cuenta de lo que scrive diferente de los otros o reformar los abusos que ay oy en ella, se pudiesse aprovechar de su autoridad (1950/1609: 9).

\subsection{La problemática del modelo idiomático se planteó de manera semejante} en América -con las propias referencias diatópicas, y con la inclusión del

4 Esto es de elemental sentido común, y, así, mi cotejo del Diálogo de la Lengua con un manuscrito coetáneo de la misma ciudad natal del humanista erasmizante muestra grandes coincidencias lingüísticas entre los dos corpus, pero también algunas diferencias, a buen seguro resultantes de la diversa formación, incluso del propio oficio, de cada autor.

5 No es fácil encontrar en la América preindependiente referencias concretas a la Ortografía académica, mucho menos a la Gramática, y del Diccionario se hallan solo en selectos medios y situaciones especiales, no se registran en la novela de Fernández de Lizardi, por ejemplo; en impreso cartagenero del año 1812 en el cual El Curioso rebate al que trata de Amigo Incógnito sobre cuestiones jurídicas y políticas, cuando escribe: "¿Qué significa el verbo requerir? El Diccionario dice que es intimar, o avisar, o hacer saber alguna cosa", exacta definición del Autoridades, y donde el autor tras emplear babuchas remite a pie de página: "Este nombre no lo trae el Diccionario; pero es una voz provincial" (Vanegas Useche 2011: 367-368). 
indígena bilingüe y del esclavo o criado negro para el contraste normativo-, y Fernández de Lizardi es un ejemplo de ello, también el de los cultos que, preocupados por el buen hablar, no lo refieren a directriz institucional alguna, y así en su extensa novela ninguna cita ni alusión hay para la Real Academia Española, no obstante que sí tenga muy en cuenta el saber ortográfico, que considera imprescindible para el maestro de primeras letras, y del que estaba ayuno el que Periquillo tuvo en su primera experiencia escolar:

Es verdad que tenía su tintura en aquella parte de la escritura que se llama Calografía, porque sabía lo que eran trazos, finales, perfiles, distancias, proporciones, etc., en una palabra pintaba bonitas letras; pero en esto de Ortografia no había nada. Él adornaba sus escritos con puntos, comas, interrogaciones y demás señales de estas, mas sin orden, método ni instrucción; con esto salían algunas cosas suyas tan ridículas que mejor le hubiera sido no haberlas puesto ni una coma..., que donde había de poner dos puntos, ponía coma; en donde esta tenía lugar, la omitía, y donde debía poner dos puntos, solía poner punto y final (Fernández de Lizardi 2008/1816: 119).

Es muy posible, pues, que El Pensador Mexicano tuviera en cuenta las normas publicadas en la Ortografía académica, aunque había otras, y una variedad notable en esta materia, sobre todo en la manuscritura ${ }^{6}$. Reprocha este autor los "mil desatinos" que estaba expuesto a cometer "el que carece de instrucción en la ortografía", sobre todo si esos "mil groseros barbarismos" se producían a la vista de todos, en anuncios comerciales, en los papeles de las esquinas y aun en el cartel del Coliseo:

Es corriente ver una mayúscula entremetida en la mitad de un nombre o verbo, unas letras por otras, etc. Como, verbigracia: Chocola Tería famosa, Rial estanquiyo de puros y cigaros, El Barbero de Cebilla, La Horgullosa, El Sebero Dictador, y otras impropiedades de este tamaño, que no solo manifiestan de a legua la ignorancia de los escribientes, sino lo abandonado de la policía de la capital en esta parte (120-121).

\footnotetext{
6 Como en varios sitios he señalado, y en el caso de este autor debe tenerse en cuenta su excelente formación y su obra escrita, parte publicada en periódicos, en los cuales se solía tener cuidado con el aspecto formal, máxime en los de una gran ciudad como México. Y la variación ortográfica podría darse en el propio individuo o en su entorno, como, de hecho, un soneto manuscrito del mismo Fernández de Lizardi, pero del que no tengo seguridad de que sea autógrafo, se halla con ortografía que no coincide del todo con la que defiende en El Periquillo Sarniento: Colección de poesías mexicanas, anónimas y de varios autores, Biblioteca Nacional de España, Ms. 3167, f. 36r.
} 
Es evidente que en estas formas hay pura cacografía, pero en algunas también motivación de concretos fenómenos fonéticos que tienen que ver con el español de México de la época (antihiatismo, seseo y yeísmo), pero ahora interesa resaltar que para Fernández de Lizardi "sería deseable que no se permitiera escribir estos públicos barbarismos que contribuyen no poco a desacreditarnos" (121), en consonancia con lo que poco después pensarían Bello y Sarmiento, y otros intelectuales y polemistas americanos. Justamente observa, asimismo, que "este defecto de ortografía se extiende a muchas personas de fina educación, de talentos no vulgares, y que tal vez han pasado su juventud en los colegios y universidades", achacando principalmente tal estado de cosas "a los maestros de primeras letras", si bien "ya hoy se va remediando este abuso mediante la aplicación de nuestros profesores" (122).

1.3. A Fernández de Lizardi le preocupaba la educación de la juventud, sin duda, no solo en lo referente a la cuestión ortográfica, sino también en cuanto a la pedagogía seguida en la enseñanza de la lectura, pues "no todos los que leen saben leer" (118), y al paso del protagonista de El Periquillo Sarniento por tres escuelas de distintos maestros dedica varias páginas de su novela (116-138). Pero asimismo criticará su aprendizaje en tres años de estudio de gramática latina: "Saqué la cabeza llena de reglitas, adivinanzas, frases y equivoquillos latinos; pero en esto de inteligencia en la pureza y propiedad del idioma, ni palabra" (153). Está atento este autor a la innovación semántica en el español novohispano: "Allí no había sino un braserito de barro que llaman anafe, cuatro o seis petates enrollados..." (653, en vez de 'hornillo'), "se debe... hacerlos bañar (a los niños) con frecuencia y si es posible en agua fría, o, cuando no, tibia o quebrantada, como dicen" (113), "los mozos bailadores, o, como les dicen, útiles" (298), "siguen brincando y saltando muy serenos, contentándose con lo que ellos llaman caldo...; este caldo es el manoseo que tienen con vuestras hijas y mujeres" (299), a la sinonimia indígena local, "nodriza o chichigua, como acá decimos" (108), al arcaísmo léxico en la vestimenta de varón, "su vestido cuando lo fui a ver era una bata hasta los pies de aquellas que llamaban de quimones, llenas de flores y ramaje" (532), incluso a la diversidad sociolingüística: "una niña de la villa de Jalapa..., una de aquellas muchachas que ustedes los mexicanos llaman payas" (404).

Su interés por el lenguaje le hace recrearse en el léxico propio de tahúres y otras gentes marginadas (341-343, 363-365, 606-607), o en el de los marineros (708) y colegiales (156). Fernández de Lizardi en varias ocasiones se detiene en la valoración social del tuteo, así en "con esta confianza nos comenzamos todos a tutear alegremente", para él "costumbre ordinaria de 
personas malcriadas" (382) 7 . En el relato novelesco "usa un estilo casero y familiar, que es el que usamos todos comúnmente y con el que nos entendemos y damos a entender con más facilidad", pero "no omite muchas veces valerse de los dicharachos y refranes del vulgo, porque su fin fue escribir para todos", dicho del autor por el supuesto editor, esto sin prescindir de "usar de la chanza, tal cual vez, para no hacer su obra demasiado seria" (938). De manera que en las frecuentes contraposiciones entre el hablante culto y el vulgar que en su relato novelesco se suceden hay una evidente intención de comicidad, semejante a la de los diálogos quijotescos en los que interviene Sancho Panza, de la que sin duda disfrutarían lectores que difícilmente pertenecerían a la clase popular, a la que El Pensador Mexicano no consideraba carente de capacidad expresiva y de razonamiento: "Tú hablas mal, pero dices bien", le reconoce Perico a Andrés, aprendiz y criado de barbero (506). En cualquier caso, la sucesión de estampas sociolingüísticas le dan pie al autor para ejemplificar su idea del papel que la buena educación tenía en la progresión social del individuo y del país. El americanista en Fernández de Lizardi tiene la oportunidad de allegar valiosísima información sobre el español de México a las puertas de la Independencia, así como sobre los modelos lingüísticos que muchos de sus hablantes seguían.

\section{LA LENGUA DEL INDIO BILINGÜE}

2.1. Dado el interés de Fernández de Lizardi por relacionar la expresión idiomática del individuo con su clase social, en El Periquillo Sarniento no podía faltar la figura del indio de hablar "entre mexicano y castellano", así el humilde vendedor de loza al que en atropellada huida derriba con todas sus ollas y cazuelas:

Luego que lo vi, me serené de mi susto advirtiendo que no era yo el objeto que pretendían alcanzar; pero este consuelo me lo turbó el demonio del indio, que en un momento y arrastrándose como lagartija salió de debajo de su tlapestle de loza, y afianzándome del pañuelo me decía con el mayor

\footnotetext{
$7 \quad$ En nota a pie de página precisa: "El tratamiento del tú, lejos de aumentar la amistad como creen algunos vulgares, la disminuye; porque a la demasiada confianza ordinariamente sigue el menosprecio, a este el sentimiento, y al sentimiento el enojo, y a dios amistad. Un tratamiento político y cariñoso conserva los buenos amigos".
} 
coraje: ---Agora lo veremos si me lo pagas mi loza, y paguemelosté de prestito, porque si no, el diablo nos ha de llevar horita horita. ---Anda noramala, indio macuache, le dije ¿qué pagar ni no pagar?, ¿y quién me paga a mí las cortadas y el porrazo que he llevado?

---¿Yo te lo mandé osté que los fueras atarantado y no lo vías por dónde corres como macho azorado? ---El macho serás tú y la gran cochina que te parió, le dije; indigno, maldito, cuatro orejas; acompañando estos requiebros con un buen puñete que le planté en las narices con tales ganas que le hice escupir por ellas harta sangre.

Dicen que los indios luego que se ven manchados con su sangre se acobardan; mas este no era de esos. Un diablo se volvió luego que se sintió lastimado de mi mano, y, entre mexicano y castellano, me dijo: ---Tlacatecolo, mal diablo, ladrón jijo de un dimoño, agora lo veremos quién es cada cual; y diciendo y haciendo, me comenzó a retorcer el pañuelo con tantas fuerzas que ya me ahogaba, y con la otra mano cogía ollitas y cazuelas muy aprisa y me las quebraba en la cabeza (582-583).

2.2. No es esta la única ocasión en que Fernández de Lizardi hace intervenir en su novela al bilingüe indígena con deficiente dominio del español, recurso arraigado en la literatura americana y que aseguraba el efecto cómico en el lector, o en el espectador si de representación teatral se trataba ${ }^{8}$. Una segunda vez será el gobernador de indios que acude a la casa del subdelegado de Tula cuando iba a tener lugar la disputa entre Periquillo y el cura del lugar:

A este tiempo fue entrando el gobernador de indios con sus oficiales de república, prevenidos de tambor, chirimías y de dos indios cargados con gallinas, cerdos y dos carneritos. Luego que entraron, hicieron sus acostumbradas reverencias besando a todos las manos, y el gobernador le dijo al subdelegado:-Señor mayor, que los pase su mercé muy felices en compañía de estos señores para amparo de este pueblo.

Inmediatamente le dio el xóchitl, que es un ramito de flores en señal de su respeto, $\mathrm{y}$ un papel mal picado y pintado con uno al parecer verso.

8 En el mismo corpus que acabo de citar (n. 6): Coloquio de Nuestra Señora de Guadalupe; de José Protasio Beltrán (fs. 43r-52v), con intervención del indio Juan Diego en el diálogo, en cuya lengua es corriente mirosté, osté, y continuos magre, pagre por madre, padre, como el Pegros de la copla funeraria (cfr. 2.3). 
Todo el congreso se alborotó, y se trató de que se leyera públicamente. Uno de los padres vicarios se comidió, y guardando todos un perfecto silencio comenzó a leer el siguiente

\section{SUÑETO}

Los probes hijos del pueblo, con prósperas alegrías, te lo venimos a dar los días con carneros y cochinos. Recibalosté placenteros con interés to mercé, como señor josticiero, perdonando nuestro afeuto las faltas de este suñeto porque los vivas mil años y después su gloria eternamente.

Todos celebramos el suñeto, repitiendo los vivas al subdelegado y los repiques en los platos y vasos, mezclados con empinar la copa, unos más, otros menos, según su inclinación (550-551).

La intención burlesca de esta estampa no precisaba de mayor aclaración, pero el autor no se priva de demostrarla: "Luego que se retiraron los indios, comenzaron todos a celebrar el suñeto, que andaba de mano en mano; pero con disimulo, porque no lo advirtieran los interesados" (552).

2.3. Se repetirá el caso en el último capítulo, que narra el funeral del protagonista novelesco, Perico, aquí ya don Pedro, cuando los amigos del difunto van escribiendo en la losa de tecal del sepulcro varios epitafios, el primero en latín y los demás en sonetos, décimas, una octava y una quintilla, además de "la siguiente coplilla que le hicieron escribir al indio fiscal de San Agustín de las Cuevas:

La dicha copla, después de muchos comentos que sobre ella hicimos a causa de que estaba ininteligible por su maldita letra, sacamos en limpio que decía:

Con esta y no digo más:

Aquí murió señor don Pegros, que nos hizo mil favores, so mercé no olvidaremos

Ya no hubo quien quisiera escribir nada después que oyeron alabar la copla del indio; $\mathrm{y}$ así nos entretuvimos en copiar los versos con la ayuda de un lápiz que por fortuna se encontró en la bolsa de don Tadeo (936). 
2.4. Los pasajes citados ofrecen unos cuantos rasgos fonéticos y gramaticales, que el autor maneja con inequívoca intención de caracterización sociocultural. En 2.1 presenta la variación vocálica vulgar en osté ("¿yo te lo mandé osté...?", paguemelosté) y en dimoño, amén de la aféresis de la $a$ - en horita, lexicalizada en el español popular de México. En el consonantismo se señala la pérdida de la /-d/ en osté, la palatalización de $/ \mathrm{n} /$ más la semiconsonante anterior que le sigue (yod secundaria o romance), que popularmente en español de demonio puede dar demoño (como almunia y Antonio ocasionalmente resultan almuña y Antoño); y destacable es la presencia de jijo con la inicial aspiración procedente de la /f-/ etimológica, que de Andalucía y de otras hablas meridionales pasó a América9 .

En cuanto a la morfología, además de la locución adverbial acriollada de prestito, el temporal agora, por entonces ya de rústicos pero que en el español clásico aún era variante aceptada de ahora, a semejanza de lo que sucedía con el imperfecto vía, todavía usual en el Quijote, en relación con veía: agora y vía aún hoy se oyen entre campesinos españoles. Sintácticamente se apunta la tendencia americana a prodigar el pronombre de tercera persona catafórico, forma redundante que se halla en "agora $l o$ veremos quién es cada cual", "¿yo te lo mandé osté que los fueras atarantado y no $l o$ vias por dónde corres...?". En esta última frase desde luego el los de "los fueras atarantado" es una forzada deturpación gramatical en artificiosa caracterización de la "lengua de indio". Y está el tratamiento de tercera persona (osté) con el tuteo (fueras, vías, corres), aborrecido por Fernández de Lizardi.

En 2.2 se reitera mercé sin - $d$, pero con el correcto posesivo antepuesto (su mercé), esto en el breve pasaje en prosa que al gobernador de indios le corresponde, salvo por dicha elisión consonántica propio de un autor culto; habida cuenta de que días es 'cumpleaños', inmediatamente antes se lee "con ocasión de haber ido yo a darle los días por ser el de su santo", nada de particular tiene los en "que los pase su mercé muy felices".

En cambio el texto en verso recupera el cariz tópico del personaje indígena en la literatura colonial, aun cuando en él no haya jijos, sino el canónico hijos, pues ya no hay posesivo normal su con mercé, sino to por

$9 \quad$ Y que, por más que, incluso con marbete académico, algunos aún se empeñan en negar la realidad histórica, su primera $j$ se pronunció siempre igual que la interior, como una $/ \mathrm{h} /$ meridional y americana que en absoluto es alófono de la $/ \mathrm{x} /$ norteña, sino confluencia de la antigua aspiración castellana y de la evolución dialectal de las prepalatales fricativas, sorda y sonora, medievales. De este misma forma (jijo) encuentro muestras en manuscritos sevillanos de 1588 y 1589: hiho, jija, jijos (1993: 451), hihos en carta de 1571 de extremeño asentado en México (1999: 50), y jijo, arraigado en la República Dominicana, pervive en México en expresiones interjectivas (Santamaría 1978: 636). 
tu (to mercé), de nuevo mixto de tercera persona y de segunda, y suñeto resulta arbitraria deformación fonética de un término culto como soneto es; culto también, aunque no tan especializado es justiciero con su $u$ átona cambiada en $o$, fenómeno de más fácil atribución al bilingüe indígena. Se repite osté (recibalosté) y un lo redundante, "te lo venimos a dar los días", en singular por plural, para significar la torpeza gramatical del indio, y en placenteros podría darse el mismo caso, ahora plural por singular, si el adjetivo se refiere al subdelegado homenajeado en su cumpleaños, no si califica a los días (recibalos osté).

Finalmente, lo mismo que probes y mercé, al nivel vulgar pertenece el relajamiento resultante en vocalización de la /-k/ implosiva de afecto (afeuto), fenómeno no exclusivo de América, pero de mayor arraigo en su español rural.

En 2.3, de nuevo en verso, el indio fiscal reitera un posesivo fonéticamente anómalo en el tratamiento personal (so mercé), no marca con preposición este complemento directo, elide el artículo con señor don Pegros, y el nombre de persona el autor lo aindia pluralizándolo y alterando su $d$ en $g$ (cfr. n. 8). Todavía introduce fugazmente El Pensador Mexicano al indio en su novela, y este, apenas conocedor del español, deforma cristiano en quistiano cuando, espantado por la carnicería que le hace Perico en su oficio de torpe rapador, escapa gritando: “Amocuale, quistiano, amocuale!” Que fue como decirme en castellano: -" No me cuadra tu modo, señor, no me cuadra”.

\section{EL LENGUAJE CARCELARIO}

3.1. En la primera experiencia de cárcel del aún inexperto Perico, su desconocimiento del lenguaje que allí se manejaba le depara un amargo lance con el preso de confianza, "un hombretón gordo con un chirrión amarrado en la cintura", que le exige "dos y medio; o no sé cuánto de patente":

Yo, que ignoraba alquel idioma, le dije que no quería asentarme en ninguna cofradía en aquella casa, y, así, que no necesitaba de patente. El cómitre maldito, que pensó que me burlaba de él, me dio un bofetón que me hizo escupir sangre diciéndome: -iSo tal!, y me lo encajó, nadie se mofa de mí, ni los hombres, contimás un mocoso. La patente se le pide, y si no quieres pagarla, harás la limpieza, so cucharero (394). 
Esta amarga experiencia era el anuncio de la promiscuidad racial y cultural que en aquel siniestro recinto lo iba a envolver, poblado de peligros para él:

Por mi desgracia, entre tanto hijo de su madre como estaba encerrado en aquel sótano, no había otro blanco más que yo, pues todos eran indios, lobos, mulatos y castas, motivo suficiente para ser en realidad, como fui, el blanco de sus pesadas burlas (424).

Resulta inevitable, pues, que:

Habiéndose acostado mis concubicularios, comenzaron a burlarse de mí con espacio diciéndome:-Conque, amigo, ¿también usted ha caído en esta ratonera por cucharero? ¡Buena cosa!, ¿conque también los señores españoles son ladrones?, y luego dicen que eso de robar se queda para la gente ruin.

-No te canses, Chepe, decía otro; para eso todos son unos, los blancos y los prietos: cada uno mete la uña muy bien cuando puede. Lo que tiene es que yo y tú robaremos un rebozo, un capote o alguna cosa ansí; pero estos cuando roban, roban de a gordo.

-Y cómo que es ansina, decía otro, yo apuesto a que mi camarada lo menos que se jurtó fueron doscientos o quinientos; y ¿a que compone, eh? ¿a que compone? (425-426)

El primer párrafo de personaje carcelario presenta una sola nota de hablar rústico o vulgar, contimás 'cuanto más', ninguno el segundo; únicamente la del adverbio ansí el tercero, con la variante ansina el cuarto, donde el pronominalizado hurtarse aparece con la aspiración/h/ de la/f-/ etimológica, identificada con la procedente de las prepalatales medievales, que en el castellano norteño dieron $/ \mathrm{x} /$.

3.2. Debe señalarse este discordante tratamiento literario del comportamiento idiomático de unos mismos personajes de baja extracción social, que se repetirá en otros pasajes de la novela de Fernández de Lizardi, más que por descuido del autor por la dificultad extrema que supondría componer una obra de tan gran extensión, con intervenciones de tantos personajes, manteniendo su diversidad lingüística por el criterio sociocultural, que a veces se sustancia con una sola forma, así el contimás de la primera de estas citas o el ansí de la tercera.

Pero Fernández de Lizardi era plenamente consciente de que la situación social y la cultura del individuo determinaban su competencia idiomática, en cuanto al criterio de los buenos y malos usos. De ello da no pocas pruebas 
en su obra, una muy significativa al tratar del fullero cortabolsas Aguilita, en algún momento lo llamará Aguilucho, perverso compañero de prisión, "un mulatillo gordo, aplastado, chato, cabezón, encuerado y demasiadamente vivo atrevido" (448). Este truhán en sus numerosos parlamentos se conduce con la corrección del personaje más culto de la novela, de modo que Periquillo se siente obligado a observar:

-No pensé jamás que un hombre de tu pelaje hablara tan razonablemente; porque, la verdad, y sin que sirva de enojo, los de tu clase no se explican en materia ninguna de ese modo.

A lo que el nombrado Aguilita, Aguilucho o Gavilán responde:

-Aunque no es esa regla tan general como la supones, me contestó, sin embargo es menester concederte que es así por la mayor parte; mas esa dudeza e idiotismo que adviertes en los indios, mulatos y demás castas, no es por defecto de su entendimiento, sino por su ninguna cultura ni educación.

Concluyendo:

Yo, por ejemplo, hablo regularmente el castellano porque me crié al lado de un fraile sabio, quien me enseñó a leer, escribir y hablar. Si me hubiera criado en casa de mi tía la tripera, seguramente a la hora de esta no tuvieras nada que admirar en mí (450-451).

3.3. Pero en la cárcel no solo se hacinaban malhechores de toda laya y condición, marginados asiduos de sus celdas y sótanos, sino también hombres del campo y provincia a los cuales un mal suceso pudo llevar a tan duro encierro. En esta novela será el caso de don Antonio Sánchez, en el relato novelesco natural de Orizaba, de padres que "fueron de buena cuna y arreglada conducta", quien a los diez años fue puesto en el colegio después de que, según confiesa a Periquillo, "entre nodrizas, ayas y criadas pasé mi puerilidad..., sin dejar de aprender aquellos principios de religión, urbanidad y primeras letras, en que no se descuidó de instruirme mi amante padre" (398). Así que este recluso se expresará con la corrección de los más cultos en las conversaciones que con Periquillo mantiene a lo largo de muchas páginas de la novela (394-447). Por el contrario, "un pobre payo que estaba también preso", quien dice ser "de San Pedro Escapozaltongo, que estará de este ciudá como diez y ocho leguas" (468), tiene una extensa intervención, necesariamente objeto de un próximo estudio, cuajada de 
modismos rústicos y no exenta del estereotipo lingüístico y literario, de la cual tomo un breve pasaje para marcar algunas concomitancias respecto de los textos arriba analizados:

Ya llevo tres meses de prisión y no sé qué harán conmigo, aunque Lorenza me ha escribido que ya Culás está bueno y sano y anda tocando la guitarra. Pues yo, señor, quero que me haga el favor, pagando lo que juere, por el santo de su nombre y por los güesitos de su madre, de escrebirme dos cartas: una para mi padrino, que es el señor barbero de mi tierra, a ver si viene a componer por mí estas cosas, y otra para la alma mía de Lorenza, diciéndole cómo ya sé que salió del depósito, y que todavía Culás la persigue, que cuidado como va a hacer una tontera, que no sea ansina y todas las cosas que sepa, señor, que se deben poner; pero como de su mano, que yo lo pago (470-471).

Como en el lenguaje de indio se ha visto, el del campesino se adoba de vulgarismo vocálico en Culás y, seguramente de manera forzada, aun contando con la interferencia analógica, en quero, siendo escrebir (escrebirme) antigua disimilación que tuvo carta de naturaleza literaria durante siglos, alternante con escribir en el período clásico, pero que ya había perdido entre los cultos la aceptación de antaño. En el consonantismo están los casos de güesitos y juere, cuya aspiración inicial ha de ponerse en relación con la de jijo del indio y jurtó del presidiario. Morfológicamente con escribido y ansina, forma esta con las correspondencias ansí y ansina en boca de los presos. Claro es que otras semejanzas se dan entre el habla del payo preso y la de indio, sea la pérdida de la $-d$ en ciudá, o la vocalización de la $/ \mathrm{k} /$ implosiva en defeuto (468).

Y para una visión de conjunto lo más precisa posible del tratamiento que la diversidad sociolingüística recibe en El Periquillo Sarniento, no estará de más observar cómo, igual que son de nivel culto algunas elocuciones de condenados a cárcel de baja estofa, lo son las de los léperos que en la novela figuran como asiduos frecuentadores de accesorias o lugares inmundos donde se practicaba el juego de azar en los arrastraderitos, "truquitos o billarcitos indecentes", y otra gente carne de prisión, entre ellos "ni una cara blanca", todos "lobos y mulatos encuerados", que, sin embargo, aparte del tono burlesco y de la nota escatológica, y de algún vocablo propio de los de su clase, ninguna incorrección gramatical o fonética cometen en sus intervenciones $(350,353,380-381)$. 


\section{EL HABLA DE LA MUJER VISTA POR FERNÁNDEZ DE LIZARDI}

4.1. Fernández de Lizardi se muestra misógino, y, sin embargo, la presencia de la mujer es recurrente en el relato novelesco, con diversidad de papeles sociales y detenida atención de este autor a algunos de los caracteres y comportamientos que juzga propios del elemento femenino, también en lo que a su trato en público respecta, sin descuidar la nota cultural y el refinamiento de costumbres, naturalmente inherentes al lugar que cada mujer ocupara en la sociedad, independientemente incluso del nacimiento fuera de la que aún era capital virreinal. Es lo que se desprende de la mención que don Antonio Sánchez hace de su casamiento "con una niña de la villa de Jalapa, quien a una cara peregrina unía una bella índole y un corazón sencillo; en fin, era una de aquellas muchachas que ustedes los mexicanos llaman payas" (404), con la cual asentado ya en la ciudad de México, añadirá:

A los dos días trajo el sastre los túnicos, que le venían a mi mujer como pintados, pues era tan hermosa de cara como gallarda de cuerpo. Fuera de que, aunque era payita, no era de aquellas payas silvestres y criadas entre las vacas y cerdos de los ranchos; era una de las jalapeñas finas y bien educadas, hija de un caballero que fue capitán de aquellas compañías o regimientos que llaman de Tres Villas y por aquí conocerá usted cuán poco tendría que aprender de aquel garbo, o lo que llaman aire de taco las cortesanas $(405)^{10}$.

Esta jalapeña "fina y bien educada", aunque payita para el habitante de la ciudad de México, se expresa con total corrección en el espacio novelesco que se le concede (430-433), mientras la mísera viuda de la rural Tixtla en su conversación con el avariento cura de esta localidad justifica su analfabetismo, “¡Ay, señor cura!, ¿para qué quiero este papel si no sé leer?”, con un tres veces dicho su mercé, en todo lo demás de lenguaje canónico, y sin marca vulgar alguna cuando habla ante el clérigo compasivo que la había socorrido (676-678). Y cuando el autor por medio de Perico atribuye el coloquial albear al uso de las mujeres, es claro que se refiere a las empleadas en el servicio doméstico, o todo lo más a las de humilde condición:

10 Santamaría, que cita esta mismo pasaje de El Periquillo, recoge la expresión darse uno taco 'darse pisto, darse importancia' (1978: 993). 
Esa noche cenamos y me fui a acostar sin meterme en más dibujos. Al día siguiente nos dio chocolate la recamarerita, hizo la cama, barrió, atizó el cobre, porque plata no la había, y puso la casa albeando como dicen las mujeres (494).

4.2. La recamarera Luisa no tiene mácula lingüística en el episodio de su amorío con Perico en casa del pedante Chanfaina, ni aun cuando movida por los celos arremete contra Lorenza, "una muchacha de no malos bigotes", a la que trata de "esa grandísima tal...", respondiéndole la ofendida con el tratamiento popular de ella: "No, eso de tal, dijo Lorenza toda encolerizada, eso de tal lo será ella y su madre y toda su casta". Interviene entonces nana Clara contra Luisa: "Eso no, grandísima cochina, lambeplatos, piojo resucitado, a mi sobrina no, tal; agora verás quién es cada cual" (495-496). El aspecto vulgar de la refriega se sustancia con el ella de Lorenza, y el agora junto al coloquial lambeplatos de la cocinera. Bien y mal habla la criada joven de una acomodada viuda de México, con la segunda modalidad en el último de sus párrafos, con el asendereado su mercé y el vulgar desgote 'descote, escote':

¡Ay, señor!, dijo la muchacha; en mucho, en mucho. Mire su mercé..., como que cuando salí a la tienda o a la plaza no más me andaba atajando; por señas que ese rosario que tiene el señor es mío, que ayer me agarró ese pícaro del desgote de la camisa y del rosario, y me quería meter en un zaguán, y yo estiré y me zafé, y hasta se rompió la camisa, mire $s u$ mercé... (392).

La cocinera de los padres de Periquillo, la nana Felipa, en una ocasión se sirve del anteriormente reiterado asina: "ahora, hijito, ya se murió, y es fuerza que vaya a buscar mi vida..., y asina ¿qué hemos de hacer?” (331) ${ }^{11}$. La vieja mujer del barbero al que Perico servía se expresa de forma correcta hasta que, "hablando medias palabras de cólera”, exclama: “¡Ah, grandísimo bellaco, atrevido!, hora te enseñaré..." (509). Y el vulgarismo de otra pobre vieja de "desierta boca" se marca con su corrupción de un latinismo, cuando

11 En otra intervención de nana Felipa, de correcta construcción lingüística, se desliza un insistión, así está en la edición que manejo, que parece ha de tomarse por alteración de ingestión, en un contexto en el que la criada se queja de cómo han dejado la casa después de una fiesta jóvenes perdularios con sus vómitos y otras suciedades: “¡Ay, qué gentes van a los bailes de tan mala insistión que no contentos con tragar, divertirse, emborracharse y emporcar la casa, todavía hacen mil maldades como esta" (304). 
al consejo de Periquillo, "no hable usted, señora, que se le meterá el aire y le corromperá la mandíbula", la martirizada por el aprendiz de sacamuelas replica: "¡Qué malíbula ni qué demonios! ¡Ay, Jesús!”12. Finalmente, en el encuentro de Perico, en su papel de falso médico, con la mujer y las hijas del alcabalero de Tula, personaje acomodado por tanto y a la sazón enfermo de aparente gravedad (538-540), estas intervienen en el diálogo con absoluta corrección, en la modalidad normal del español mexicano (“¡Ay, Jesús, gritó una de las niñas, ya se murió mi padrecito!"), hasta que la dueña de la casa, ante el latinajo del impostor ("encargando mucho que no lo resupinaran"), encolerizada replica con alguna muestra de vulgarismo idiomático:

-¿Qué es eso de resupinar, señor dotor?, preguntó la señora. Y el cura sonriendo le dijo:

-Que no lo tengan boca arriba. -Pues, tatita, por Dios, siguió la matrona, háblenos en lengua que nos entendamos con la gente.

Lo mismo que una de las muchachas, recuperada de su desmayo:

-Sí, señor, mi madre dice muy bien; sepa que por eso me privé endenantes, porque como empezó a rezar aquello que los padres les cantan a los muertos cuando los entierran, pensé que ya se había muerto mi padrecito y que usted le cantaba la vigilia.

4.3. Son las mujeres de Tula, adineradas por el cargo del padre de familia pero provincianas, las mejor caracterizadas cultural y lingüísticamente, mediante la pregunta de la madre sobre resupinar, con la que el autor aparenta su ignorancia (cfr. n. 12), y con el empleo del vulgar dotor, completada la estampa con el rústico endenantes de la hija. Las demás figuras femeninas llevan las siguientes marcas lingüísticas: su mercé la primera, la segunda ella 'usted', lambeplatos y agora, la tercera el asendereado su mercé y desgote, nana Felipa, la cuarta, asina, y, tal vez, insistión por ingestión (v. n. 11), la quinta, anciana mujer del barbero, por el hora con aféresis, la sexta, la vieja a la que Perico le destroza las quijadas, con el deforme malíbula, recurso burlesco del autor para resaltar la incultura de la anciana, y terminan la lista las familiares del alcabalero de Tula.

El discordante comportamiento normativo de unos mismos personajes al que arriba me refiero (cfr. 3.2) se produce con mayor reiteración en el

12 Con el remedo de este nuevo cultismo, la Academia lo recogió en 1817, y no mucho antes Terreros, el autor busca el doble efecto que con el resupinar de la esposa del alcabalero de Tula, marcar la pobreza idiomática de estas mujeres y provocar la hilaridad en el lector. 
caso de las mujeres, pues todas las ahora señaladas por sus vulgarismos lingüísticos también se manejan como hablantes correctas en estas mismas intervenciones suyas. No solo eso, sino que otros personajes femeninos que deberían aparecer con rasgos de hablantes vulgares o populares, no los presentan en sus respectivos papeles. Así, Luisa, criada hermana de "un ladrón conocido y harto criminal" (480-481, 495-496, 643-644), las mujeres disolutas o de la hoja (254-255), incluso Anita ("trapientona rolliza y no muy fea"), pícara del monipodio del barrio de Necatitlán (656). En cambio, es natural que hablara bien la jalapeña "fina y bien educada" (405, 430-433), esposa de don Antonio Sánchez, el culto preso (cfr. 3.3.), ni resulta extraño que lo fuera la hija de este personaje, criada en un convento, que al final de la trama novelesca aparecerá para casarse con Periquillo, convertido ya en un respetable don Pedro (906-907).

\section{EN RESUMEN}

5.1. En lo que precede queda manifiesta la mayor dificultad que el autor encuentra en la descripción normativa referente a la mujer, a cuyo grupo socialmente bajo atribuye los mismos rasgos lingüísticos con los que caracteriza a los hablantes masculinos, pero con menor frecuencia de los mismos, como con toda evidencia se demostrará con su presentación novelesca del criado varón, también con la del campesino, frente a la que aplica a la criada, caracterización sociolingüística también más parca que la del indio bilingüe. Y, sin embargo, la suma de notas de tipo vulgar que Fernández de Lizardi va desgranando en su novela resulta sumamente útil para determinar el modelo popular y rústico del español mexicano en la Independencia.

Guarda a veces El Pensador Mexicano la relación entre buen hablar y hablante de buena cuna con la instrucción escolar. Se advierte la buscada conexión en la desdichada Isabel, hija de encumbrado personaje, a quien dirige emocionada carta antes de expirar en su obligado encierro conventual, misiva situada en el polo opuesto del vulgarismo (594-595), como culto es el billete en el que Poncianita responde a las pretensiones amorosas de Perico (255). Y, aunque en miserable situación, de notable corrección es la historia que de su vida cuenta María Guadalupe Rosa, "mis padres fueron nobles y honrados, y aunque no ricos, tenían lo suficiente para criarme como me criaron, con regalo..." (873-878). Ya se ha visto, sin embargo, que la tipificación normativa de los grupos sociales de bajo nivel que escenifican 
la trama de El Periquillo Sarniento no alcanza a todos sus integrantes, ni abunda el autor en su perfil idiomático, connotado por unos pocos modismos vulgares, salvo en las que son intervenciones de criados varones y campesinos, pero semejante objetivo ni se lo plantearía, ni habría sabido cumplirlo Fernández de Lizardi, que con frecuencia únicamente se sirve del realismo en materia de lengua suficiente para aderezar de "veracidad" la historia del protagonista y al mismo tiempo plasmar en la novela su pensamiento ilustrado.

5.2. Con todo lo dicho, no resulta raro el tratamiento que nuestro autor da a la familia propietaria de una gran hacienda, cuyo titular "don Martín, que así se llamaba el amo, era bastante liberal y rico", a quien toma como principal representante del hablante campesino en un extenso diálogo con el vicario de Tlalnepantla, ocasión forzada en todo caso, pues la condición social del terrateniente era bien distinta a la de un pobre payo, para enfrentar el modelo culto al vulgar. En cambio la esposa del hacendado y sus hijas hablan correctamente, salvo cuando una de ellas se refiere a la cometa y el clérigo le reprocha: "el cometa dirá usted, señorita" (174). En el episodio de la hacienda el género de esta voz se toma por referencia de la condición sociolingüística de cada interviniente, el antiguo femenino en todos los participantes en el diálogo, incluido Perico, a pesar de su título de bachiller recién ganado, en masculino exclusivamente en boca del vicario, en la ocasión representante del selecto hablar. El caso de don Martín, tomado como tipo de usuario del habla rústica, no pasa de ser un fácil pretexto para el juego del contraste sociocultural por medio de la expresión idiomática, igual que es que Perico una vez refuerce el superlativo absoluto con el adverbio muy:

-Pues, señores, los cometas, o las cometas como otros dicen, son unas estrellas más grandes que todas las demás; y después de que son tan grandes, tienen una cola muy larguísima... - ¿Muy larguísima?, dijo el vicario. Y yo, que no conocía que se admiraba de que ni castellano sabía hablar, le respondí lleno de vanidad: - Sí, padre, muy larguísima, ¿pues que no la ha visto usted? -Vaya, sea por Dios, me contestó (177) ${ }^{13}$.

13 A partir de ahí en este diálogo Perico alterna la cometa y el cometa. Más adelante don Martín, hablando como payo con el vicario, dirá “creo que el mundo es mucho más grandísimo que el sol" (198). 
Es la única vez en que el protagonista de El Periquillo Sarniento se significa como hablante no perteneciente a la mejor clase, y que tenga una reprimenda por ello, aunque tampoco aquí sea caracterizado de rústico o vulgar, pues evidentemente había grandes dificultades para establecer tipos sociolingüísticos intermedios. Alguno de ellos tendría que corresponder al barbero (500-502), al sargento de guardia y al sereno (390-393), o a Ciriaco Redondo, al tendero de Tula (544), de elocuciones ajenas a cualquier incorrección. Difícil en efecto tenía que ser la precisión en esta cuestión lingüística, cuando en la misma novela de El Pensador Mexicano se encuentra un satisfaceré seguramente no marcado, puesto en boca de un escribano real y receptor de la Real Audiencia (486), si no es con fin burlesco, cuando ya en el Quijote se halla satisfaré (II, 3). Y el mismo Fernández de Lizardi, que critica el antihiático rial 'real' (cfr. 1.2), en el texto de su novela al lado de tompeate $(654,661)$ desliza un tompiate $(667)$.

5.3. Con todas las precauciones que el caso requiere, y con los problemas que Fernández de Lizardi tendría a la hora de tratar literariamente con un mínimo de congruencia argumental la diversidad sociolingüística de México, es lo cierto que en los retazos de contraste lingüístico que ofrece se registran no pocos datos objetivamente válidos para encarar cada vez con mayor rigor la variación normativa en la América de las independencias, y no es solo en $E l$ Periquillo Sarniento donde este autor atiende a la repercusión sociocultural en el uso del lenguaje ${ }^{14}$. Pero, más allá de los pasajes que se suelen llamar "marcados", la novela de El Pensador Mexicano es un compendio del español americano de la época, y del mexicano en particular, cuyo conocimiento por parte de los lingüistas evitaría considerar la transferencia del número plural del se complemento indirecto al complemento directo lo (lat. dativo + acusativo) como fenómeno "en formación", cuando era general en América a principios del siglo XIX, y sistemático en la obra de este autor, por ejemplo, "Dios se los pague", "a todos se los contaba" $(287,630)$, lo mismo que el uso de gente 'persona, individuo', "como catorce o diez y seis gentes había allí", "era capitán de cazadores de gentes" $(380,386)$, frecuente el de ojalá y, "ojalá y yo hubiera sabido" (363), y el de la variación de género, verbigracia en guitarristo y macha 'mula' $(469,533)$. Definitivo también es este corpus para el estudio del tratamiento personal, con el de ustedes

14 En otros escritos suyos, Fernández de Lizardi plantea esta problemática en el habla de sus personajes, así en la fábula El payo y el colegial (1963: 300-301). 
por vosotros, el de construcciones como "ya yo los tenía en la mía", "ya yo contaba" $(357,736)$, el del pretérito perfecto simple y compuesto y otras cuestiones verbales, el de medio adverbial, también con variación de género, vulgarmente connotada: "no tiene más defeuto sino que es media bizca" (468), o el de la acusada presencia de leísmo y laísmo en la lengua escrita americana. Meros botones de muestra de la información que el americanista en El Periquillo Sarniento puede obtener.

\section{REFERENCIAS BIBLIOGRÁFICAS}

Acosta, CRistóbal De. 2005/1578. Tratado de las drogas y medicinas de las Indias Orientales, con sus plantas debuxadas al bivo. Edición facsímil. Valladolid: Editorial MAXTOR.

Alemán, Mateo. 1950/1609: Ortografía castellana. Edición de José Rojas Garcidueñas y estudio preliminar de Tomás Navarro. México.

Fernández de Lizardi, José Joaquín. 1963. Obras, I. Poesías y fábulas. Edición de Jacobo Chencinsky y Luis Mario Schneider. México: Universidad Nacional Autónoma de México. -2008, 2. ${ }^{a}$ ed./1816. El Periquillo Sarniento. Edición de Carmen Ruiz Barrionuevo. Madrid: Ediciones Cátedra.

Inca Garcilaso de la Vega. 1989/1590. La traduzión del indio de los Tres Diálogos de Amor de León Hebreo, hecha de italiano en español. Edición facsímil. Sevilla: Padilla Libros.

Frago Gracia, Juan Antonio. 1993. Historia de las hablas andaluzas. Madrid: Arco/Libros. 1999. Historia del español de América. Textos y contextos. Madrid: Gredos. 2002. Textos y normas. Comentarios lingüisticos. Madrid: Gredos.

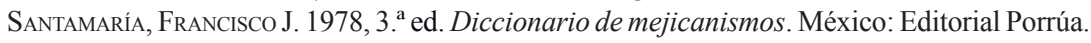
VAnegas Useche, Isidro (ed.). 2011. Dos vidas, una revolución. Epistolario de José Gregorio y Agustín Gutiérrez Moreno (1808-1816). Bogotá: Editorial Universidad del Rosario. 